\section{Pacific Northwest}

National Laboratory

Operated by Battelle for the

U.S. Department of Energy

\section{New York State Code Adoption Analysis: Lighting Requirements}

\author{
E. E. Richman
}

September 2004

Prepared for the U.S. Department of Energy under Contract DE-AC06-76RL01830 


\title{
New York State Code Adoption Analysis: Lighting Requirements
}

\author{
E. E. Richman
}

June 2004

Prepared for

the U.S. Department of Energy

Office of Building Technologies

under Contract DE-AC06-76RL01830

Pacific Northwest National Laboratory

Richland, Washington 99352 


\section{Summary}

The state of New York has asked the U.S. Department of Energy to analyze the potential energy effect and cost-effectiveness of the lighting requirements in the 2003 IECC as they consider adoption of this energy code. The new provisions of interest in the lighting section of IECC 2003 include new lighting power densities (LPD) and requirements for automatic lighting shutoff controls. The potential effect of the new LPD values is analyzed as a comparison with previous values in the nationally available IECC codes and ASHRAE/IESNA 90.1. The basis for the analysis is a set of lighting models developed as part of the ASHRAE/IES code process, which is the basis for IECC 2003 LPD values. The use of the models allows for an effective comparison of values for various building types of interest to New York state. Potential effects from control requirements are discussed, and available case study analysis results are provided but no comprehensive numerical evaluation is provided in this limited analysis effort.

The numerical LPD analysis concludes that the change in weighted average power density requirements across all building types is estimated to be a decrease of 0.39 watts per square foot. The corresponding estimated change in installation costs to meet these requirements is a decrease of $\$ 0.88$ per square foot as a result of reduced fixture requirements. The new controls requirements are found to be cost effective on a whole building weighted basis at a payback period of well under 5 years. 


\section{Table of Contents}

Summary ................................................................................................................... ii

Lighting Power Densities - Cost Effectiveness...............................................1

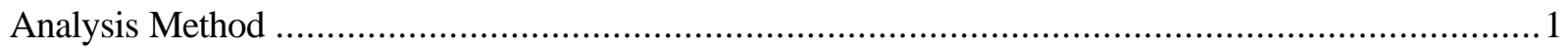

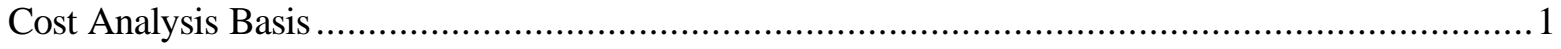

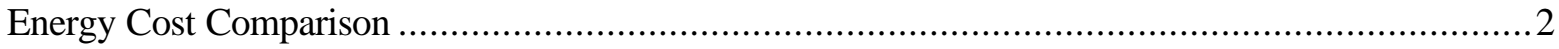

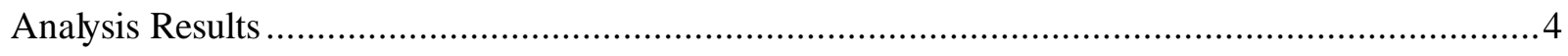

Additional Adoption Considerations ..........................................................6

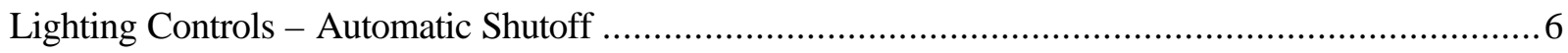

Compliance and Additional Lighting Power Allowances............................................................

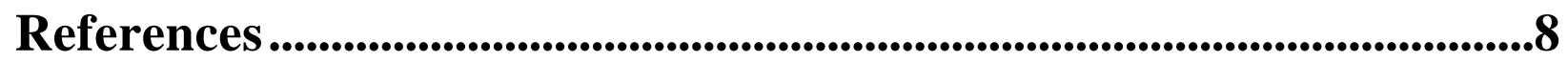




\section{Tables}

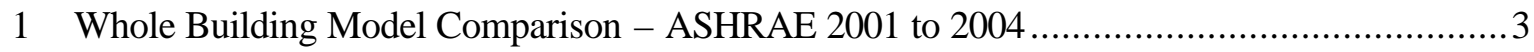




\section{Lighting Power Densities - Cost Effectiveness}

The adoption of the IECC 2003 Energy code will include a set of Lighting Power Density (LPD) values that are effectively a subset of the values in Addendum $g$ to the ASHRAE/IESNA/ANSI 90.1-2001 Standard, and printed as part of the 90.1-2004 version. An analysis of the effectiveness of this adoption for New York State can be provided by a direct comparison of these values with existing LPD levels represented in the current IECC 2000 code, which are themselves a subset of the current ASHRAE/IESNA/ANSI 90.1-2001 Standard (without addenda). Because the complete ASHRAE 2001 and 2004 sets of LPDs are supported by a set of detailed models, they are best suited to provide the basis for an analysis that compares the two code levels of lighting power density stringency.

It is important to note that this kind of analysis is a point-to-point comparison, where a fixed level of real world activity is assumed. It is understood that buildings are not built precisely to code levels, and that actual percentage of compliance above and below codes will vary among individual buildings and building types. However, without specific knowledge of this real world activity for all buildings in existence and in the future (post-code adoption), it is not possible to analyze actual effects of code adoption. However, it is possible to compare code levels and determine the potential effect of changes from one code requirement level to another. This is the comparison and effectiveness assessment provided by this analysis.

\section{Analysis Method}

The basis for this analysis is the set of models that are used to derive the LPD values in the ASHRAE and current IECC nationally adopted codes. The basic models are mathematical representations of typical "good quality" lighting designs for approximately 120 different space types commonly found in buildings. The output of these models is a LPD for each space type, which forms the space type LPD requirements in the Standards. These space type LPDs are further applied to a dataset of detailed space type square footage data take-offs for 246 individual, recently constructed real buildings from across the nation. This application generates whole building LPDs based on the weighting of space type LPD values in real buildings. The dataset contains multiple individual buildings for each building type, and the LPD results for these are averaged to represent a typical building type LPD requirement.

\section{Cost Analysis Basis}

These ASHRAE 90.1 LPD models are modified for the New York State analysis to generate cost effectiveness data. The original models provide information on generic lighting technology types and the relative quantities of each that represent the lighted space type. This lighting technology information is directly used to develop a typical cost for each space type model for both the ASHRAE 2001 (basis for IECC 2000) and the ASHRAE 2004 (basis for IECC 2003) sets of models. These derived space type costs can then be compared and combined with estimated energy savings to develop the cost-effectiveness of the adoption of the new LPD values.

Cost data for commodities such as lighting are always very difficult to apply to analysis efforts because of the great variability. Lighting products that provide similar light at similar efficiencies and distribution 
characteristics can come in a wide variety of styles and formats that have greatly varying costs. This is unlike other major building energy components such as mechanical systems and envelope materials, where the cost is generally driven by the efficiency or quantity of the material. Lighting, however, includes a very large decorative or visible art component that impacts cost.

To make this analysis a fair and reasonable comparison, a set of equitable costs was required. The basis for these depends on the use of basic light producing equipment (minus any decorative or art components) at a nationally consistent and recognizable cost structure. The LPD models are already based on standard basic equipment representing good quality but low decorative components. The source for consistent cost data is centered on the R.S. Means cost data reference (RS Means 2001) and the Grainger Supply catalog (Grainger 2004). The R.S. Means data is a well recognized and used source for building construction cost estimating that provides material, labor, and overhead estimates for a variety of lighting products. R.S. Means also tracks location-specific cost indexes for adjusting basic cost data. The Grainger Supply catalog represents a major retail source of lighting equipment with nationally consistent prices. The Grainger catalog provides additional detail on specific equipment that is not available in the Means data source and is used to supplement the base Means estimates.

Each of the LPD models is populated with lighting fixture data from 1 to 3 different fixture types from a list of 34 defined fixture types. Fixture costs for each of the 34 types were developed from the two cost sources, which are in turn applied to the space type models. This development included deriving a base fixture cost and associated installation labor, adjustment to NY cost indexes, and assignment of a wattage for cost assignment. The Means and Grainger sources were used, where applicable, to derive an installed cost for each fixture. The Means city cost indexes for New York cities were used to derive a weighted New York state index using city population data from the U.S. Census. The resulting costs used for this analysis include material plus labor adjusted by the weighted New York state index but do not include any overhead/profit adders. The Grainger catalog was used to assign a typical wattage to each fixture type. These wattages are used to apply the appropriate cost for each of the one to three fixture types in the model based on the model s use of them based on wattage and efficacy.

The individual space type model formulas were modified to derive costs (instead of LPD) based on the developed fixture costs and index. While the set of ASHRAE 2001 and 2004 models are the same, some of the characteristics of the models are different including different fixture choices and, of course, the quantities of fixtures needed to provide the lighting represented by the LPD value. These differences drive the difference in cost for each model from the 2001 to 2004 sets of models. For consistency of the analysis, the efficiencies of the fixtures applied in the models and the building set data used to develop the whole building values were based (for both code levels) on the latest data used in the 2004 Standard development. This provides a consistent basis because new construction designed to meet either code would apply the same equipment at current efficiencies.

\section{Energy Cost Comparison}

The models provide detailed data that can be used to compare individual space type characteristics and changes. However, these individual comparisons cannot provide an overall effect on code adoption at a state level. Therefore, the whole building cost data derived in the analysis is used for comparisons. The models are used to derive both difference in cost and difference in energy (power density) between the 
application of IECC 2000 and 2003 LPD levels to each building type. The cost difference is the difference between the whole building lighting cost per square foot derived using the ASHRAE 2001 models and the ASHRAE 2004 models. The energy difference is the wattage (power density) difference per square foot. These values for the 32 building types are shown in Table 1.

Table 1. Whole Building Model Comparison - ASHRAE 2001 to 2004

\begin{tabular}{|c|c|}
\hline Building Type & $\begin{array}{l}\text { "Change" } \\
\text { in \$/sqft }\end{array}$ \\
\hline
\end{tabular}

$\begin{array}{lcc}\text { Automotive Repair } & (1.20) & (0.60) \\ \text { Convention Center } & (0.25) & (0.20) \\ \text { Courthouse } & (0.79) & (0.20) \\ \text { Dining-Bar Lounge/Leisure } & (0.29) & (0.20) \\ \text { Dining-Café/Fast Food } & 0.11 & (0.40) \\ \text { Dining-Family } & 0.40 & (0.30) \\ \text { Dormitory } & (3.33) & (0.50) \\ \text { Exercise Center } & (0.13) & (0.40) \\ \text { Fire Station } & (0.66) & (0.50) \\ \text { Gymnasium } & (0.02) & (0.60) \\ \text { Healthcare-Hospital } & (1.16) & (0.40) \\ \text { Hotel } & (2.48) & (0.70) \\ \text { Library } & (0.32) & (0.20) \\ \text { Manufacturing } & (1.35) & (0.90) \\ \text { Motel } & (2.99) & (1.00) \\ \text { Multi-Family } & (0.43) & (0.30) \\ \text { Museum } & (0.86) & (0.50) \\ \text { Office } & (1.00) & (0.30) \\ \text { Parking Garage } & 0.12 & 0.00 \\ \text { Penitentiary } & (0.68) & (0.20) \\ \text { Police Station } & (0.74) & (0.30) \\ \text { Post Office } & (1.46) & (0.50) \\ \text { Religious } & (1.45) & (0.90) \\ \text { Retail } & (1.96) & (0.40) \\ \text { School-College } & (0.31) & (0.30) \\ \text { Sports Arena } & (1.17) & (0.40) \\ \text { Theater-Performing Arts } & 0.04 & 0.10 \\ \text { Theatre-Motion Picture } & (0.54) & (0.40) \\ \text { Town Hall } & (0.87) & (0.30) \\ \text { Transportation } & (0.16) & (0.20) \\ \text { Warehouse } & (0.29) & (0.40) \\ \text { Workshop } & (0.22) & (0.30) \\ & & \\ & & \end{array}$

It is clear from the table that the majority of the building types (28) exhibit both a decrease in cost and a decrease in energy between the two code levels. For these cases, there is a clear advantage in both cost and energy to moving to the new code level. The remaining four building types are worth examining individually. 


\section{Dining - Cafeteria Fast Food}

The energy savings of 0.40 watts per square foot for this building type will offset the additional equipment cost. This is calculated using an estimated weekly lighting operation time for this building type of 84 hours (EIA 1999, Commercial Bldg Energy Conservation Survey) and the 2003 yearly average NY State Commercial electricity cost of 13 cents per kilowatt (U.S. DOE 2004). For this building type, the estimated simple payback is 0.47 years.

Dining - Family

The energy savings of 0.30 watts per square foot for this building type will also offset the additional equipment cost. In this case, the estimated simple payback is 2.4 years.

\section{Parking Garage}

The parking garage building type is the only one that experiences no change in lighting power density for whole building. The whole building values represent aggregations of multiple individual space types and building space characteristics. These combinations of changes in the models can produce a null effect such as this for energy with a definite effect in cost (or visa-versa). In this case, while there is no energy savings, there is a small increase in cost resulting from small changes in technology choices. Therefore, technically, the additional small cost per square foot will never be repaid with energy savings for this building type.

\section{Performing Arts Theatre}

In this case both the cost and energy are expected to increase with a change in code levels. The cost change is very small at $\$ 0.04$ per square foot with a moderate rise in energy use at 0.10 watt per square foot. Again in this case, there can be no repayment of the additional equipment cost for this building type.

To be able to evaluate the effect of the code change across New York, it is important to look at the weighted effect of all building type changes. In the absence of NY State specific data, a national representation of building square footage by building type (EIA 1999) was used to weight the effect of the code change. The results of this analysis are a weighted decrease in equipment cost of $\$ 0.88$ per square foot for all buildings and a decrease in energy of 0.39 watts per square foot for all buildings.

\section{Analysis Results}

Primary results from this comparison analysis are:

- 31 of the 32 building types analyzed show a decrease in allowed power density with adoption of the new code. The Performing Arts Theatre building type increases by 0.1 watt per square foot allowed (1.5 to 1.6) and Parking Garage shows no change in energy.

- 28 of the 32 building types show estimated decreases in lighting installation cost in complying with the new IECC 2003 code LPD levels. This is primarily caused by the new models reflecting the current light level recommendations and applying current equipment efficiencies and design practices that allow less equipment to be able to provide the necessary lighting. Cafeteria/Fast Food Dining, Family Dining, Parking Garage, and Performing Arts Theatre building types experience small to moderate increases in equipment costs. 
- The weighted average power density change across all building types is an estimated decrease of 0.39 watts per square foot in lighting power density across the state based on a typical nationwide building mix.

- The weighted average effect of the cost change across all building types is an estimated decrease in lighting installation costs of $\$ 0.88$ per square foot across the state based on a typical nationwide build ing mix.

These results make it clear that on a State level adoption of the new lower LPD values found in the IECC 2003 and ASHRAE 90.1-2004 are cost effective at effectively any cost recovery base period and well below a 10-year recovery base.

It is important to note that while this analysis can do a reasonable job of comparing code levels, it is in no way a metric for actual practice, and, therefore, actual effects of the code. Builders have and will continue to design buildings (and lighting) based on client needs and desires, with energy code compliance, at best, a companion consideration. Therefore, it is probable that some (or many) buildings are already designed better than existing codes and may require minimal or no change to meet future codes. 


\section{Additional Adoption Considerations}

\section{Lighting Controls - Automatic Shutoff}

The major change in the 2003 IECC code from 2000/2001 versions in lighting controls is a requirement for automatic lighting shutoff in spaces greater than 250 square feet, in buildings larger than 5000 square feet. This requirement is intended to eliminate what is considered one of the largest remaining lighting energy losses in commercial buildings - lights on when unoccupied. The requirement can be met by one of two basic options: 1) a whole building controller, and/or 2) occupancy sensor controls. The savings potential from automatic control has been studied, and the results indicate large but quite variable potential. It is generally impossible to evaluate actual savings potential given the multiple variables of the building stock and use characteristics for an entire State. However, some discussion of the effect of this requirement can be useful.

For very large buildings, this requirement can likely be met with the capabilities of the whole building control systems commonly found in these structures. This is option 1 of the requirement that allows for sweep controls of lighting by floor or large area (with override provisions). While there is no specific language to this effect, lighting in spaces that are occupied on a 24-hour basis would typically be exempt from this requirement.

For small buildings ( $<5000$ square feet), these requirements do not apply, and at least for whole building control, would not likely be cost effective.

For the remaining moderately sized buildings, a whole building controller may already be a part of the design, and the lighting control capability may already be in place. For buildings without this capability, option 2 of the requirements, which allows occupancy based control, may be the best option. The language of option 2 is decidedly unclear. This language has been corrected in the ASHRAE $90.1-2001$ Standard but remains unclear in the 2003 IECC. The intent of this option is to poin t specifically to occupancy sensor type controls. This option provides the capability of saving much more energy than sweep controls and has an element of added flexibility. However, it is not clear that these controls are always cost-effective. Research finds that some building spaces are better candidates than others for these sensors both from a cost-effectiveness and operational standpoint. For example, most of the study results show that "common" type spaces such as lunchrooms, conference rooms, restrooms, and/or photocopy rooms provide the best energy savings opportunities. Conversely, those studies show that some but not all individual offices can provide little savings. This of course depends on the mindset of the occupant of the individual office, which varies widely. The use of sensors throughout a building does ensure that all potential savings is harvested. While the conditions are extremely variable, some of the study work shows potential payback periods for occupancy sensors in the range of 0.7 to 7.8 years (depending on capacity of installed lighting) for "common" spaces and 4.0 to 9.1 years for office type spaces based on Federal energy rates of around $\$ 0.08$ per $\mathrm{kWh}$ (below the NY rate). From an operational standpoint, the use of occupancy sensors in some spaces is still met with skepticism or opposition. Some organizations/individuals may be concerned with sensors in restrooms or other spaces, where automatic loss of light may be inconvenient or a safety issue. While the energy code cannot take precedence over 
safety issues, the definition of where this could be an issue is not covered in the energy code language and would have to be addressed by local or State building officials.

It appears from available case study data that at least option 2 of the requirement is likely cost-effective considering a simple 10-year payback limit for any specific space type with a weighted payback period well under 5 years for whole buildings. The issue of appropriate application of this requirement given its limited language will likely be important for consistency. It may be appropriate for the State to prepare some specific guidance and/or interpretation of this requirement for local officials to follow.

\section{Compliance and Additional Lighting Power Allowances}

In addition to the cost effectiveness considerations for new code adoption, other factors may merit consideration. It is clear that in a state such as New York, where culture and design are a prominent feature (particularly in larger cities), that lighting design can be an important part of design, art, and commerce. There has already been evidence (conference call May $26^{\mathrm{a}}$ ) that interested parties may be concerned with a new set of requirements that appear to drastically restrict lighting design with much lower LPD levels.

It is also understood by code developers that the prominent art element of lighting (not found in envelope and mechanical energy concerns) creates potential problems with meeting specific code levels. This is the driver behind the additional lighting power allowances provided in the ASHRAE and IECC codes. Because of the unfamiliarity of codes and application, some interested parties may not have a full understanding of the use of the additional allowances. Therefore, the adoption of more stringent codes such as IECC 2003 or ASHRAE 90.1-2004 could be eased within the lighting design community by emphasis and education placed on these allowances. It was clear from the May 26 conference call discussions that design of common or typical buildings was not an issue even with the new code levels but rather the individual high-end retail or community structure, where the additional allowances can provide relief. Adoption of the IECC 2001 code also provides an automatic avenue for LPD relief in the form of the alternate compliance path of compliance to the 90.1-2001 Standard referenced in Chapter 7 of the IECC code that includes the older set of LPD values.

\footnotetext{
${ }^{a}$ Pacific Northwest National Laboratory staff participated via a conference call in a meeting of the New York State Technical Subcommittee for the Energy Conservation Construction Code was attended on May 26, 2004. The potential adoption of the IECC 2003 energy code was discussed. William Warren, lighting consultant from New York, spoke on the issue of the new more restrictive lighting power density requirements in the 2003 IECC. He expressed concern that some retail and other artistically lighted facilities may have trouble meeting these restrictive power densities requirements while still saving energy by other means such as advanced lighting controls. Mr. Warren was interested in New York exploring the adoption of a modification of the 2003 IECC for NY that would credit facilities for energy savings from advanced controls against these tight power densities.
} 


\section{References}

Energy Information Administration (EIA). 1999. Commercial Building Energy Consumption and Expenditures Survey 1999 (CBECS 99), U.S. Department of Energy. Washington D.C.

Energy Information Administration (EIA). 2004. Electric Power Monthly, June 2004, EIA website: http://tonto.eia.doe.gov/FTPROOT/electricity/epm/02260406.pdf, U.S. Department of Energy.

Washington D.C.

R.S. Means. 2001. RS Means Electrical Cost Data $24^{\text {th }}$ Annual Edition 2001. R.S. Means, Kingston, Massachusetts.

W.W. Grainger. 2004. Grainger 2004-2005 Catalog No. 395. W.W. Grainger, Lake Forest, Illinois. 